\title{
Treatment of Fracture Head Radius in Children with Closed Reduction and Elastic Nail
}

\author{
Salama F. ${ }^{1}$, Elshoura S. ${ }^{1}$, Mandour I. ${ }^{1}$ \\ Orthopedic surgery Department, Faculty of medicine, Al-Azhar University \\ (Damietta) \\ Corresponding author: Ibrahim Mandor, email: docmandour@gmail.com
}

\begin{abstract}
Background: radial head fractures represent $5-10 \%$ of traumatic injuries of the elbow in children and $1 \%$ of all pediatric fractures. They result from a fall on the outstretched arm, with the elbow extended and the forearm supinated.

Objective: this study aimed to assess the results of treatment of fracture head radius in children with closed reduction and fixation with elastic nail. The results were assessed clinically and radiologically. Methods: this study included 20 patients with fracture head radius in children who were treated with closed reduction and elastic nail in the Department of Orthopedic at New Damietta Al-Azhar University Hospital from Jan 2018 to September 2018.

Results: this study was carried out on twenty patients with epiphyseal fractures of head radius treated with elastic nail from Jan 2018 to Oct 2018 and follow up for (1-10) months, 16 case excellent, 2 cases good, one case fair and one case bad. Conclusion: we were convinced by the versatility of the Titanium Nancy nailing as it provides a solution to fracture head radius that would have been exposed to open reduction, with no wasting time during operation, less infection rate, less blood loss and improved rehabilitation program.
\end{abstract}

Keywords: fracture head radius in children with closed reduction and elastic nail.

\section{INTRODUCTION}

Displaced radial head and neck fractures are rare injuries in children, with an incidence of 1$5 \%$ of all elbow fractures in children. The most incidence is between 5 and 15 ages and fall on the outstretched arm with the elbow extended, which causes valgus compression on the radial head, that defined as the injury mechanism ${ }^{(1-2)}$. The best choice of the treatment depends on the degree of the radial head angulation, which are mostly affects the long-term results. Then a lot of classification systems based on the degree of displacement, degree of angulation and the presence of the associated injuries or no association, were introduced ${ }^{(3-4)}$. A relatedliterature showed that for severe or moderate angulated fractures, reduction of the displaced head must be performed either conservative or surgical before casting ${ }^{(5)}$. However, reduction with hand manipulation is acceptable if only the stable construct is persistent. But surgical techniques vary as percutaneous reduction with K-wires, Nancy nail fixation and open reduction with or without internal fixation ${ }^{(6-7)}$. Open reduction is used only in communited fractures and cases where closed reduction has failed due to various disadvantages. Intramedullary technique which was the only one who described by Metaizeau ${ }^{(5)}$ in 1980 further developed to Nancy nail fixation technique in 1993 by the same surgeon, allowed extracapsular but, intramedullary reduction and fixation without any need for pin removal surgery besides ${ }^{(8-9)}$.

\begin{abstract}
Aim of work
This study aimed to assess results of treatment of fracture head radius in children with closed reduction and fixation with elastic nail. The results were assessed clinically and radiologically.
\end{abstract}

\section{Patients and methods}

In this study, 20 patients (12 males, 8 females) that had fractures of head radius, aged 5 to 15 years old were operated by closed reduction and fixation with intramedullary elastic nail in Al-Azhar University Hospital in Damietta from Jan. 2018 to september 2018 Outcome after head radius fractures has traditionally been measured by invest parameters and objective physical variables. We evaluated the association between radiological position, objective physical result (range of movement), and the patient-perceived outcome, measured with the Disabilities of the arm, shoulder and elbow.

\section{Results}


This study was carried out on twenty patients with epiphyseal fractures of head radius treated with elastic nail from Jan 2018 to Oct 2018 and follow up for (1-10) months. The commonest mechanism of injury was falling from height on out-stretched hand and road traffic accidents (RTA) and sport injury Mechanism of injury

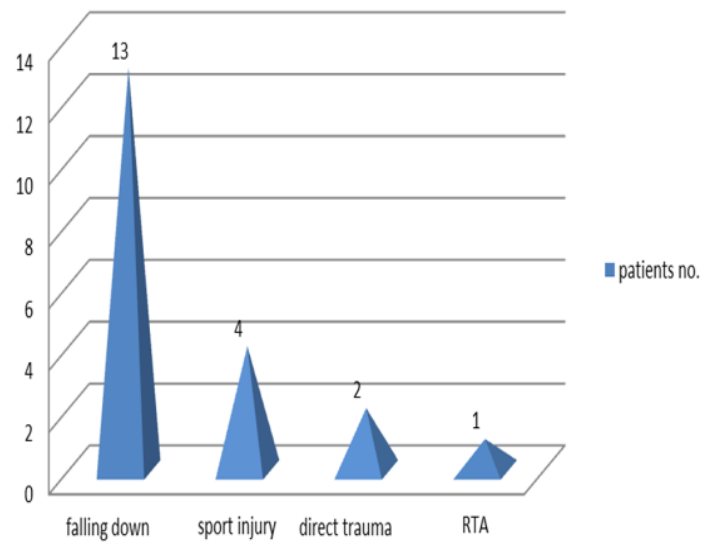

Fig 1: distribution mechanism of injuries Two patients had associated fracture (olecranon and dislocation elbow), while the others were free as shown in master table statistical results according to clinical outcome.

Table 1: showing statistical results according to clinical outcome

\begin{tabular}{|c|c|c|}
\hline Number of cases & Functional results & $\begin{array}{c}\text { No. of cases with } \\
\text { percentage }\end{array}$ \\
\hline 16 & Excellent & $80 \%$ \\
\hline 2 & Good & $10 \%$ \\
\hline 1 & Fair & $5 \%$ \\
\hline 1 & Poor & $5 \%$ \\
\hline
\end{tabular}

Table 2: show clinical outcome evaluation

\begin{tabular}{|r|r|}
\hline Outcome & Description \\
\hline Excellent & No pain, full range of motion, no deformity \\
\hline Good & $\begin{array}{r}\text { Occasional insignificant pain, range of motion decreased } \\
\text { in any direction, }<10^{\circ} \text { valgus deformity }\end{array}$ \\
\hline Fair & $\begin{array}{r}\text { Occasional insignificant pain, range of motion decreased } \\
\text { in any direction, }>10^{0} \text { valgus deformity }\end{array}$ \\
\hline Poor & Requiring further surgery \\
\hline
\end{tabular}

\section{Discussion}

The most common type of treatment of head radius fractures is closed reduction and slab immobilization, although slab immobilization alone avoids surgery and many complications, it cannot maintain the distraction to correct length or control the rotation of the distal fragment when commination is present ${ }^{(10)}$. Fracture head radius of extra-articular fracture can be managed conservatively if acceptable reduction can be achieved; otherwise surgery is necessary to obtain a good functional result ${ }^{(11)}$. In our study we used Judet and O'Brien classification to classify the radial head fracture pattern and to evaluate the post-operative complications ${ }^{(21-}$ 22). In the present study, the commonest mechanism of injury was falling on out stretched hand followed by direct trauma and lastly sport injury.

In this study 7 cases were type 3 according to Judet classification, while 13 cases were type 4.This study showed that total accident population is 20 and most of them falling on out stretched hand are highest among 5-15 years of age group. About $60 \%$ children were males. In the present study, two patients (20\%) had associated fracture (Olecranon and dislocation elbow), while the others eighteen $(80 \%)$ were free.

About intramedullary Nancy nail fixation in the fracture head radius, we had small incision over distal radius $(1 \mathrm{~cm})$ then used awl or by drill power, entrance of suitable sized elastic nail, till reaching the fracture site after that closed reduction was done, reduction helped by curve of elastic nail, Once the device was fixed, reduction is achieved. Post-operative complications: were Malunion and limitation range of motion in two cases equal $(10 \%)$ and no other complications were detected. The management of fractures of the head radius in children was controversial. In 1996, there were published the results of the treatment of gradeIV fractures by open reduction and internal, transarticular fixation (ORIF) ${ }^{(12-15)}$.

In that series, 10 out of 96 children with fractures of the neck had a grade-IV fracture. Eight were treated operatively, with one excellent (12\%) and six poor (75\%) results, while one patient (12\%) was lost to follow-up. Two were treated conservatively because of delayed referral, with a poor outcome in both (17-19). Their overall results compared very unfavorably with those published by other authors who reported excellent conclusions after ORIF in $50 \%, 43 \%, 38 \%, 33 \%$ and $\% 1$ of cases. Overall, however, the results from ORIF are not satisfactory. Only one in three patients had an excellent outcome, this indicated that this may not be the most appropriate method to 
treat these difficult fractures ${ }^{(16-17)}$.

\section{Conclusion}

This study aimed to evaluate the clinical success of treatment of the fracture head radius in children with closed reduction and elastic nail. This technique is a good way for the management of displaced head radius type 3 and 4 Judet classification and O'Brien ${ }^{(21)}$ types $2 \& 3$.

\section{References}

1-Tan BH and Mahadev A (2011): Radial neck fractures in children. J. Orthop. Surg. (Hong Kong), 19(2):209-212.

2- Steinberg E L, Golumb D, Salam R and Weintroub S. (2003): Radial head and neck fracture in children. Journal of Pediatric Orthopedics, 8:35-44.

3-Vocke AK and Von Laer L (2004): Displaced fractures of the radial neck in children, long term results and prognosis of conservative treatment. J. Pediatr. Orthop., 7: 217-222.

4-Radomisli T E and Rosen A L (2005): Controversies regarding radial neck fractures in children. Clinical Orthopedics' and Related Research, 353: 30-39.

5-Metaizeau J P, Lascombes $P$, Lemelle JL, Finlayson D, Prevot J (1993): Reduction and fixation of displaced radial neck fractures by closed intramedullary pinning. Journal of Pediatric Orthopedics, 13 (3):355-360.

6-Okcu G and Aktuglu K (2007): Surgical treatment of displaced radial neck fractures in children with Metaizeau technique. Ulus. Trauma. Acil. Cerrahi Derg., 13(2):122-127.

7-Eberl R, Singer G, Fruhmann J, Saxena A and Hoellwarth $M$ (2010): Intramedullary nailing for the treatment of dislocated pediatric radial neck fractures. Eur. J. Pediatr. Surg., 20(4):250-252.

8-Gagliardi Ida C, Mouraria GG, Funayama B, Kikuta FK, Cruz MA and Zoppi A (2016): Evaluation of children with radial neck fractures treated with flexible intramedullary nail. Acta Ortop. Bras., 24(2):81-54.

9-Kenneth J. Koval and Joseph D. Z (2006): Pediatric elbow. In: Handbook of Fractures. Lippincott Williams \&Wilkins, $3^{\text {rd }}$ ed. London.pp:500-539.

10-Silberstein MJ, Brodeur AE and Gravis ER (2009): Some vagaries of the olecranon .Journal of Bone Joint Surg., 63: 722 - 725.

11- Wang J, Chen W, Guo M et al. (2013): Percutaneous reduction and intramedullary fixation technique for displaced pediatric radial neck fractures. J. Pediatric Orthop., 22:127132.

12-Steele JA and Korr GH (2001): Angulated radial neck fractures in children; a prospective study of percutaneous reduction. J. Bone Joint Surg., 74:760-764.

13-Young

S, Letts $M$ and Jarvis J (2010): Blood supply of the radial head in children. J. Pediatric Orthop., 20:15-18.

14-Silberstein MJ, BrodeurAE and Gravis ER (2007): Some vagaries of the capitellum .Journal of Bone and Joint Surgery, 61: 244 247.

15- Herring J A (2004): Upper extremity injuries. In: Tachdjian's Pediatric Orthopaedics. $\quad 3^{\text {rd }}$ Edition, Saunders, Philadelphia, pp194-200.

16-Morrey BF (2004): Applied anatomy and biomechanics of the elbow joint. Instruction Course Lectures, 35:59-68.

17- Peterson HA (2000): Physeal fractures of the elbow. In: The Elbow and Its Disorders. Morrey BF (Ed). Saunders W B Co., Philadelphia. $3^{\text {rd }}$ ed, chapter 17. pp:219-35.

18-S. Yarer D W, Sommerfeldt S, Gehrmann and Rueger M (2007): Severely displaced radial neck fractures after minimally invasive joystick reduction and Prevot nailing: longterm course in childhood. Unfallchirug, 110: 460-466.

19-Jeffery CC (1972): Fractures of the head of the radius in children. J. Bone Joint Surg., 54(4):717-719.

20-Newman JH (1977): Displaced radial neck fractures in children. Injury, 9(2):114-121.

21-O'Brien PI (1965): Injuries involving the proximal radial epiphysis. Clin. Orthop. Relate. Res., 41: 51-8.

22-Judet $H$ and Judet J (1972): Fractures and orthopedique de l' enfant. Paris: Maloine, 78(2):31-39 